\title{
Perancangan Kampanye Cara Pintar dalam Berhemat Listrik Prabayar
}

\author{
Sutikno Try Setyo ${ }^{1)}$, Heri Iswandi ${ }^{2)}$, Yosef Yulius ${ }^{3)}$ \\ ${ }^{12) 3)}$ Program Studi Desain Komunikasi Visual Universitas IndoGlobal Mandiri \\ Jl Jend. Sudirman No. 629 KM. 4 Palembang 30129 \\ Email: trysetyo.sutikno@gmail.com ${ }^{1)}$ wandy_dkv@uigm.ac.id ${ }^{2}$, yosef_dkv@uigm.ac.id $d^{3)}$
}

\begin{abstract}
Government innovation by presenting prepaid electricity services or better known as "smart electricity" with the aim of improving service to the community. PLN introduces prepaid electricity services that can regulate and check electricity usage alone, but some people are reluctant to use prepaid electricity because it is considered more wasteful and more expensive than electricity with a postpaid payment system. The design of the Smart Way to Save Electricity Prepaid Campaign aims to invite the community and change the negative stigma that exists in the community about prepaid electricity itself. The results of this design turned out that when the design of this campaign was exhibited to the public, not a few people responded, even many of them only knew using or consuming it, without thinking about savings. From these results it can be concluded that the campaign and socialization of energy savings were very important and responded positively by the community.
\end{abstract}

Keywords : Campaign, Savings, Prepaid Electricity

\begin{abstract}
Abstrak
Inovasi Pemerintah dengan menghadirkan pelayanan listrik prabayar atau yang lebih dikenal dengan "listrik pintar" dengan tujuan untuk meningkatkan pelayanan kepada masyarakat. PLN memperkenalkan layanan listrik prabayar yang bisa mengatur sekaligus mengecek pemakaian listrik sendiri, namun sebagian orang enggan menggunakan listrik prabayar karena dianggap lebih boros dan lebih mahal dibandingkan listrik dengan sistem pembayaran pascabayar.Perancangan Kampanye Cara Pintar dalam Berhemat Listrik Prabayar ini bertujuan untuk mengajak masyarakat serta mengubah stigma negatif yang ada di masyarakat tentang listrik prabayar itu sendiri. Hasil dari perancangan ini ternyata saat perancangan kampanye ini dipamerkan ke publik, tidak sedikit masyarakat yang merespon, bahkan banyak diantaranya yang hanya tau menggunakan atau mengkonsumsi saja, tanpa memikirkan penghematan. Dari hasil tersebut dapat disimpulkan bahwa kampanye serta sosialisasi tentang penghematan energi ternyata sangat penting dan direspon positif oleh masyarakat.
\end{abstract}

Kata kunci : Kampanye, Hemat, Listrik Prabayar 


\section{Pendahuluan}

Listrik merupakan energi yang dapat diubah menjadi energi lain, menghasilkan panas, cahaya, kima, atau gerak/mekanik (Heins Frick dan Pujo L. Setiawan). Dalam kehidupan yang telah maju (modern) kehadiran tenaga litrik dirasakan sangat penting, karena listrik sangat berguna sebagai sumber tenaga dan hampir semua kegiatan memerlukan listrik. (Suryatmo F, 2014:13) Sejarah tentang penemu listrik memiliki beberapa versi. Pertama, listrik sudah ditemukan pada zaman Mesir Kuno. Kedua, listrik ditemukan oleh Thales dari Melitus dan yang ketiga, listrik ditemukan oleh Faraday. (Wink, 2016; Penemu Listrik Michael Faraday; www.penemu.co/penemu-listrik-michael-faraday; diakses 22/01/2018)

Pendistribusian listrik di Indonesia dimulai dengan dibangunnya pusat tenaga listrik di Gambir, Jakarta (Mei 1897) dan disebar luas di Medan pada tahun 1899, kemudian di Surakarta pada tahun 1902, kemudian di Bandung pada tahun 1906, di Surabaya tahun 1912 dan di Banjarmasin 1922. Pada awal pembuatannya, pusat pusat tenaga listrik ini menggunakan tenaga thermis (panas bumi). Sebelum perang dunia ke-2, pada umumnya pusat-pusat tenaga listrik dikuasai oleh perusahaan-perusahaan swasta, diantaranya yang terbesar adalah NIGEM (nederlands Indische Gas en Electriciteits Maatschappi) yang kemudian menjelma menjadi Overzese Gas en Electriciteits Maatschappi (OGEM). Sedangkan jawatan listrik tenaga air (S'land's Waterkroct Bedridjren disingkat LWB 0 Membangun dan mengusahakan seagian pusat - pusat listrik tenaga air Jawa Barat. Pada tahun 1958 pengelolaannya dialihkan ke Negara pada perusahaan umum Listrik Negara. (Wijdan, 2016; Sejarah Listrik Pembangkit;https://www.kelistrikanku.com/2016/04/seja rah-listrik-pembangkit.html; diakses 22/01/2018)

Hingga saat ini banyak inovasi Pemerintah dengan menghadirkan berbagai pelayanan dalam bidang energi listrik. Salah satunya yaitu dengan menghadirkan listrik prabayar atau yang lebih dikenal dengan "listrik pintar". Namun sebagian orang enggan menggunakan listrik prabayar karena dianggap lebih boros dan lebih mahal dibandingkan listrik dengan sistem pembayaran pascabayar. Mahalnya pemakaian listrik dan ketidakakuratan meteran listrik adalah beberapa faktor yang membuat tagihan listrik melambung. Atas pertimbangan tersebut, PLN memperkenalkan layanan listrik prabayar yang bisa mengatur sekaligus mengecek pemakaian listrik sendiri.

Cara kerja Listrik Pintar pada dasarnya mirip dengan voucher isi ulang ponsel. Pelanggan tinggal membeli pulsa listrik dengan nominal tertentu, masukkan kode token pada meteran, dan setrum listrik pun akan bertambah. Tapi, hal ini justru sangat mengganggu sebagian orang yang kadang terpaksa menggunakannya, selain bunyi pengingat pulsa yang sangat mengganggu saat berbunyi walaupun pulsa belum habis, dan yang paling menakutkan, listrik bisa mati saat pulsa habis. Hal ini seperti memberikan pekerjaan baru kepada penggunanya, seperti bayi 5 tahun, Listrik Pintar ini harus terus dijaga dan diperhatikan. Bila dibandingkan dengan listrik pascabayar, hal ini sangatlah merepotkan pengguna. Solusinya yaitu memasukan pulsa listrik sebanyak-banyaknya agar tidak mengganggu dan mati tiba-tiba pada saat yang tidak di inginkan.

Melalui meter elektronik prabayar, pelanggan dapat memantau pemakaian listrik sehari-hari dan setiap saat. Di meter tersebut tertera angka sisa pemakaian $\mathrm{kWh}$ terakhir. Bila dirasa boros, pelanggan dapat mengerem pemakaian listriknya. Selain itu pengguna tidak akan terkena biaya keterlambatan. Tidak ada lagi biaya tambahan bayar listrik dikarenakan terbebani biaya keterlambatan akibat lupa membayar tagihan listrik.

Efek yang ditimbulkan dari penggunaan listrik yang berlebihan memang tidak terlalu kita rasakan secara langsung, namun efek tidak langsung dari pemborosan tenaga listrik yang dihasilkan oleh bantuan dari pembangkit listrik yang berbahan bakar fosil (minyak bumi, gas bumi, dan batu bara) dan dalam prosesnya mengeluarkan zat $\mathrm{CO} 2$ ke udara. Secara ilmiah telah terbukti dapat mengakibatkan timbulnya efek rumah kaca dan beragam perubahan pada alam, yang telah dirasakan saat ini adalah, naiknya suhu dipermukaan bumi, naiknya permukaan air laut, dan punahnya kekayaan hayati di segala penjuru. Yang merupakan kesalahan manusia itu sendiri sebagai penguna listrik secara berlebihan yang sering disebut pemanasan global. Maraknya pencurian listrik di berbagai Kota di Indonesia, tercatat terjadi 7.500 kasus Pada Tahun 20162017, dengan kerugian mencapai 34 Miliar Rupiah. republika.com, kompas.com, detik.com. Sedangkan, berdasarkan pengalaman penulis sendiri yang pernah juga menjadi konsumen listrik prabayar, kakak penulis sebagai orang yang bertanggung jawab membayar listrik tersebut merasakan sendiri bagaimana mahal dan sulitnya penggunaan listrik prabayar itu. Mulai dari keluhan gangguan server saat membayar, lebih mahal dari listrik pascabayar pada umumya, dan keluhan lainnya.

Maka dari data di atas, penulis tertarik dan tergugah untuk mengangkat tugas akhir dengan judul "Cara Pintar dalam Berhemat Listrik Prabayar" yang terkait dengan borosnya penggunaan listrik prabayar dalam bentuk kampanye sosial. Dengan tujuan untuk menginformasikan ke masyarakat tentang tips atau cara berhemat dalam penggunaan listrik prabayar. Masih kurangnya sosialisasi langsung kepada masyarakat terhadap permasalahan diatas juga merupakan salah satu faktor mengapa penulis membuat perancangan Cara Pintar dalam Berhemat Listrik Prabayar.

Apapun yang melatarbelakangi peranan suatu perancang dalam merancang karya desain baik itu logo maupun karya desain lainnya, unsur-unsur dan nilai-nilai yang terkandung dalam bidang desain komunikasi visual harus dipahami, sehingga suatu perancangan bisa disampaikan dengan tepat sasaran (Yulius, 2016:43).

Dalam Perancangan Kampanye Cara Pintar Dalam Berhemat Listrik Prabayar ini, perancang menggunakan analisis 5W2H, yaitu : 
a. What to say, manjelaskan hal apa saja yang diangkat dalam Perancangan Kampanye Cara Pintar Dalam Berhemat Listrik Prabayar. Pemecahan masalah : mengajak masyarakat untuk menghemat penggunaan energi listrik dengan membuat berbagai media komunikasi visual yang menarik, unik, dan mudah dipahami. Respon yang diharapkan, membuat masyarakat mulai mengerti cara menghemat listrik prabayar sejak dini.

b. Why to say, untuk memberikan pengetahuan kepada konsumen istrik prabayar tentang bagaimana cara berhemat listrik prabayar.

c. Who To Say, ILM ini ditujukan kepada target sasaran yang telah ditentukan, berdasarkan pembagiannya target dibagi menjadi beberapa kategori. Berdasarkan tingkat ekonomi, disini ditargetkan untuk masyarakat menengah kebawah. Berdasarkan geografis, penduduk Kota Palembang. Berdasarkan Umur, ditujukan untuk masyarakat dengan rentan usia 20-50 Tahun.

d. When To Say, dilakukan pada peringatan hari-hari besar yang menyangkut pemerintah, khususnya bidang ESDM. Dan tidak menutup kemungkinan juga dilaksanakan pada hari-hari biasa, karena penggunaan listrik sendiri tidak mengenal waktu dalam penggunaannya.

e. Where To Say, disosialisasikan kepada masyarakat langsung dengan membuat kegiatan-kegiatan sosialisasi di lingkungan RT dan RW.

f. How to say, dengan cara membuat beberapa media komunikasi visual, contohnya ambient media, poster, brosur, dan sticker yang dapat mempermudah perancang untuk mendapatkan banyak target sasaran.

g. How Much to say, menjelaskan seberapa kuantitas dan biaya yang perlu dilakukan dalam perancangan kampanye ini dalam waktu 6 bulan.

\section{Pembahasan}

Setiap negara pastilah memiliki tujuan untuk mensejahterakan masyarakatnya. Hal ini dikarenakan kesejahteraan merupakan tolok ukur pembangunan Nasional. Oleh karena itu, pemerintah dituntut untuk memberikan pelayanan kepada masyarakat dalam rangka mewujudkan kesejahteraan. Salah satunya adalah pelayanan jasa yang sangat erat hubungannya dengan kebutuhan sehari-hari, yaitu PT PLN (Persero).

Saat ini PT. PLN (Persero) meluncurkan 2 (dua) jenis pelayanan untuk dapat menjalankan tugas dan perannya dalam pemenuhan kebutuhan di bidang ketenagalistrikan. Dua jenis pelayanan tersebut yaitu pelayanan pelanggan dan pelayanan teknik. Kedua pelayanan tersebut terdapat dalam program Listrik Pascabayar dan Listrik Prabayar.

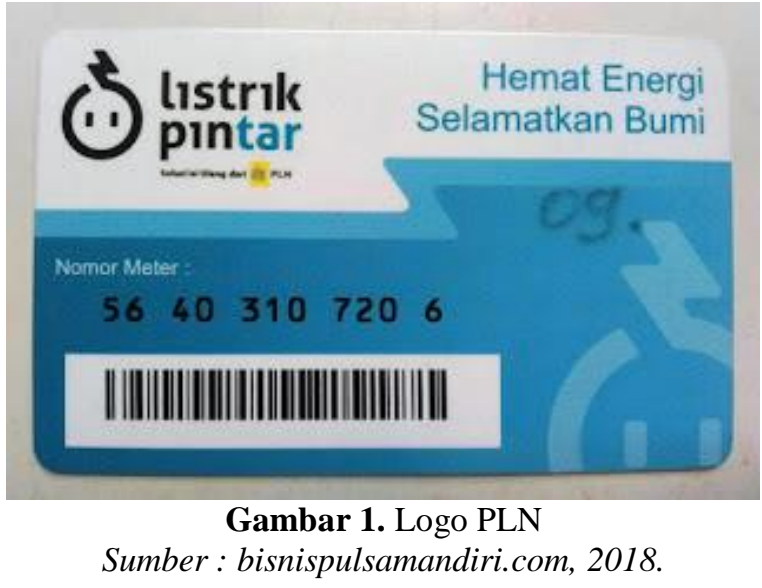

PT PLN (Persero) memberikan inovasi baru dalam pelayanan publik berupa "Listrik Prabayar" atau biasa disebut "Listrik Pintar" yang juga dilakukan oleh PT PLN (Persero) Rayon Palembang. Faktanya, pelaksanaan program Listrik Prabayar di PT PLN (Persero) Rayon Palembang masih menuai banyak keluhan di lapangan. Hal ini terlihat dalam laporan rekapitulasi keluhan pelanggan yang terpusat di PT PLN (Persero) Distribusi SUMSEL. Dengan listrik prabayar, pelanggan bisa lebih mudah mengoptimalkan konsumsi listrik, disamping itu pelanggan tidak perlu berurusan dengan pencatatan meter setiap bulan, dan tidak perlu terikat dengan jadwal pembayaran listrik bulanan. Karena persediaan kWh dapat ditambah berapa saja dan kapan saja sesuai kebutuhan dan keinginan pelanggan. Latar belakang diluncurkannya program ini sebagai wujud komitmen PLN untuk terus meningkatkan pelayanannya kepada pelanggan dengan berbagai bentuk inovasi. Selama ini banyak pelanggan mengeluhkan mengenai pencatatan meter, jumlah tagihan yang tidak menentu setiap bulan, banyak pula keluhan mengenai tagihan listrik di rumah kontrakan/kos. Dengan adanya Listrik Prabayar pelanggan dapat dengan mudah mengendalikan pemakaian listriknya sesuai dengan kebutuhan. Banyak manfaat yang didapat oleh pelanggan dengan adanya program prabayar ini, antara lain :

1. Pelanggan dapat dengan mudah memantau pemakaian listriknya setiap saat.

2. Pelanggan dapat mendisiplinkan diri sendiri untuk menggunakan listrik sesuai anggaran belanja.

3. Pelanggan tidak lagi berurusan dengan pencatat meter dan jadwal pembayaran setiap bulan.

4. Pelanggan dapat membeli token (isi ulang energi listrik) di payment point, ATM dengan jaringan yang luas dan outlet-outlet konter terdekat.

5. Tidak ada istilah menunggak.

6. Privasi pelanggan tidak terganggu.

7. Tidak dikenakan Uang Jaminan Langganan.

8. Pelaksanaan penyambungan cepat. 


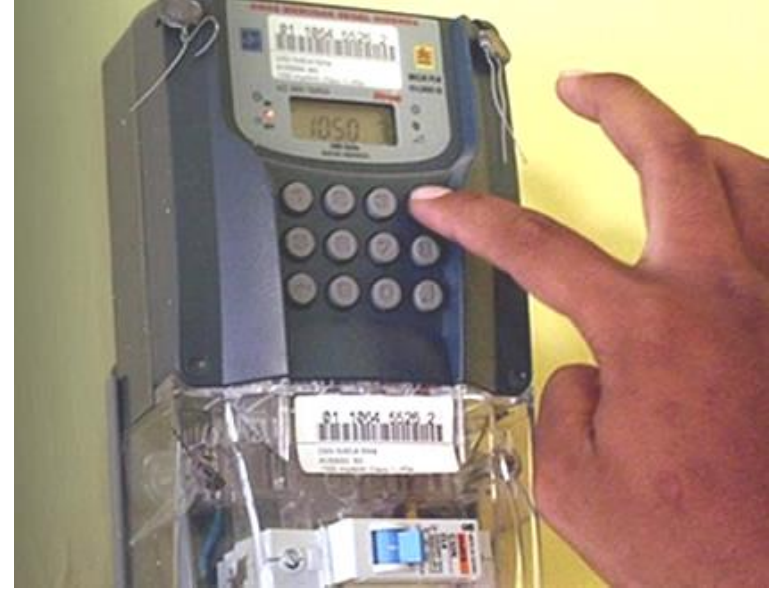

Gambar 2. Meteran Listrik Prabayar

Sumber : rayanet.id, 2018.

Kurangnya pengetahuan masyarakat Palembang tentang program listrik prabayar dikarenakan kurangnya sosialisasi dari pihak PT. PLN Palembang. Sosialisasi gencar dilakukan pada awal peluncuran listrik prabayar saja, pada saat ini sosialisasi hanya dilakukan jika masyarakat datang ke kantor. Padahal masyarakat Palembang masih ada yang belum mengetahui jelas tentang program listrik prabayar. Dan banyak juga masyarakat yang tinggal di beberapa perumahan diatas merupakan masyarakat yang merupakan pindahan dari daerah desa yang belum banyak mengetahui tentang listrik prabayar itu sendiri.

Menurut data yang ada, terjadi banyak kasus mengenai kurangnya pengetahuan masyarakat kota Palembang mengenai listrik prabayar ini. Di kota Palembang sendiri masih jarang dijumpai kampanyekampanye yang membahas tentang masalah tersebut. Perancangan ini akan mengisi kekosongan kampanye listrik prabayar di Indonesia khususnya di Kota Palembang dengan memperhatikan materi yang dibutuhkan oleh target sasaran. Melalui perancangan ini, diharapkan masyarakat dapat lebih mengetahui cara-cara berhemat listrik prabayar dan mengetahui dampak dari pemborosan listrik itu sendiri, sehingga masyarakat mulai mengerem pemakaian listrik mulai sekarang.

\section{A. Konsep Media}

Komunikasi visual tidak serta merta hanya mampu memberikan pemecahan terhadap permasalahan yang ada dan hanya berkaitan dengan eksekusi visual, namun juga mampu memilih media yang tepat dan relevan untuk membangun komunikasi dengan masyarakat ataupun pemerintah. Mural adalah salah satu media yang efektif dan akhir-akhir ini dijadikan media penyampai pesan secara visual (Iswandi Heri, 2018:Seni Mural Sebagai Unsur Politik Dalam Kehidupan Sosial)

Perancangan kampanye "Cara Pintar Dalam Berhemat Listrik Prabayar" ini memiliki konsep yaitu sebuah kampanye hemat energi yang dapat merangkul konsumen listrik prabayar (target sasaran) dan memberikan edukasi tentang cara berhemat serta dampak yang ditimbulkan dari pemborosan energi khususnya listrik prabayar. Dengan memilih Buku saku sebagai media utama, diharapkan nantinya masyarakat dapat tertarik dan mengerti apa makna yang diinformasikan melalui Buku saku tersebut, serta diharapkan dapat memiliki fungsi dan cara pemakaian yang tepat, sehingga tujuan Kampanye ini dapat tercapai. Adapun konsep-konsep media, yaitu meliputi tujuan media, strategi media, pemilihan media, khalayak sasaran, panduan media, program media, dan biaya kreatif.

Gaya desain/visualisasi pada perancangan Buku Saku sebagai media utama pada kampanye ini, yaitu menggunakan gaya Flat desain, yang memiliki karakter sederhana, minimalis bahkan menurut onlinedesignteacher.com, jagodesain.com dan situs-situs desain grafis lainnya gaya flat desain sangat digemari saat ini. Dan berdasarkan survey sederhana yang dilakukan penulis di sosial media Instagram dan Facebook, tidak sedikit para penggemar gaya desain ini bermunculan, baik dari dalam maupun luar negeri. Flat design adalah desain dengan pendekatan minimalis yang menekankan kegunaan, dengan desain yang bersih tanpa ada bevel, bayangan, tekstur, berfokus pada tipografi, warna-warna cerah dan ilustrasi dua dimensi.
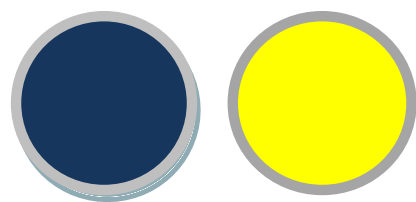

Gambar 3. Warna Utama Perancangan Dibuat Oleh : Sutikno, 2018.

Kampanye tentang tentang cara pintar dalam berhemat listrik prabayar ini menggunakan sistem warna-warna cerah. Warna biru adalah warna yang memiliki karakteristik sejuk, pasif, terang, dan damai. Warna ini melambangkan kesucian dan damai, sedangkan Warna kuning adalah warna yang paling terang setelah warna putih, karena itu warna kuning melambangkan kesenangan, kelincahan. Warna kuning adalah kumpulan dua fenomena penting dalam kehidupan manusia, yaitu kehidupan yang diberikan oleh matahari diangkasa dan emas sebagai kekayaan bumi. Kuning memaknakan keindahan, kemuliaan, cinta serta pengertian yang mendalam dalam hubungaan antara manusia.

Pada pemilihan tipe huruf atau font pada headline sebagai judul utama akan menggunakan tipe huruf "Komika Axis" yakni tipe huruf yang fleksibel, persuasif, menarik dan mudah dibaca. Lalu pemilihan tipe huruf untuk tagline, headline serta Subheadline semua sama menggunakan tipe huruf "Depot bold" yaitu font yang berisi dan memiliki aksen yang kuat, tegas sehingga mampu melengkapi headline. Adapun pembagian tipe huruf yang akan digunakan pada Perancangan Kampanye cara pintar dalam berhemat listrik prabayar yaitu sebagai berikut: 


\section{KOMIKA-AXIS \\ ABCDEFGHIJKLMNOPQRSTUWWXYZ \\ 1234567890 \\ Depot-Bold \\ ABCDEFGHIJKLMNOPQRSTUVWXYZ \\ abcdefghijklmnopqrstuvwXyz \\ 1234567890 \\ Gambar 4. Jenis Font pada Perancangan \\ Diunggah Oleh : dafont.com, 2018.}

Huruf memiliki kekuatan yang mempengaruhi sebuah desain. Setiap jenis huruf memiliki kemampuan kesan, kuat, elegan, bersahabat, tergantung dari jenis huruf yang digunakan. Pemilihan jenis huruf harus disesuaikan dengan tujuan dari desain, kepada desain ini ditentukan, dan bagaimana desain dapat menjadi solusi untuk memecahkan sebuah masalah. Dalam menentukan jenis huruf, perlu juga dilakukan identifikasi terhadap target dari segi umur, pengertian dan demografi. (Iswandi, 2018:106)

\section{B. Final Desain}

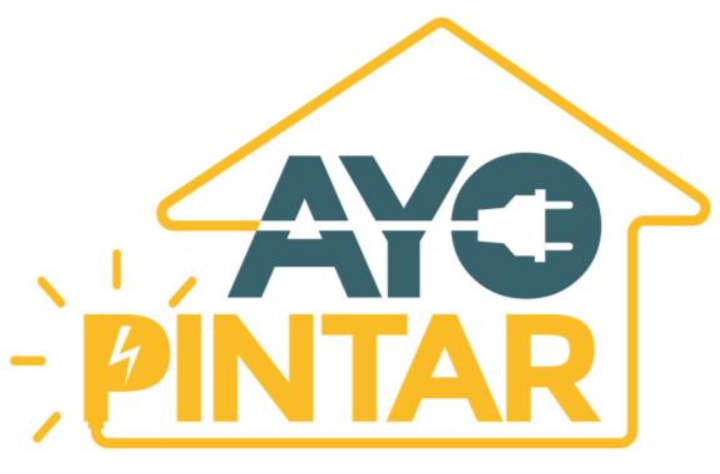

mbar 4. Final Logo Ayo Pintar

Ga

Dibuat Oleh :Sutikno, 2018.

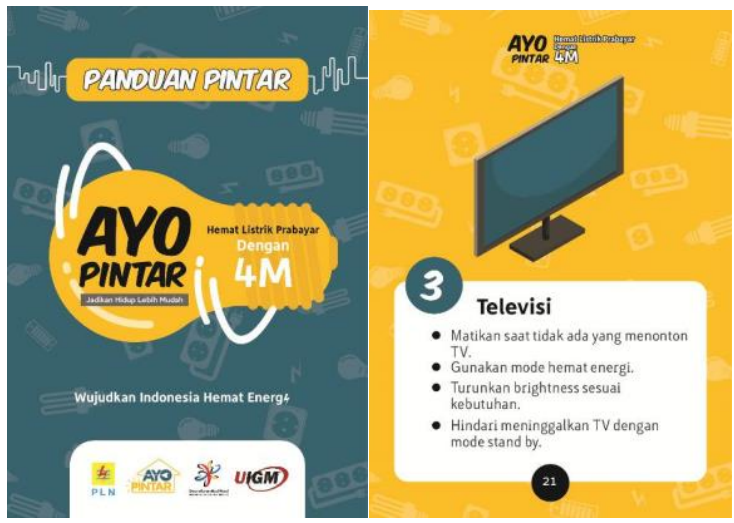

Gambar 5. Final Main Media (Buku Saku) Dibuat Oleh : Sutikno, 2018

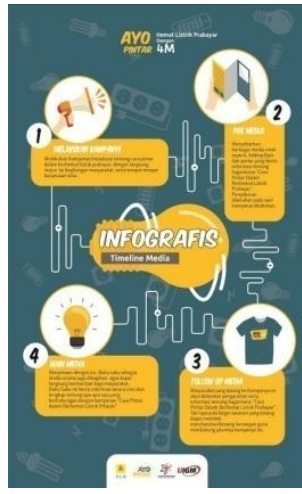

Gambar 6. Final Pre Media (Poster) Dibuat Oleh : Sutikno, 2018

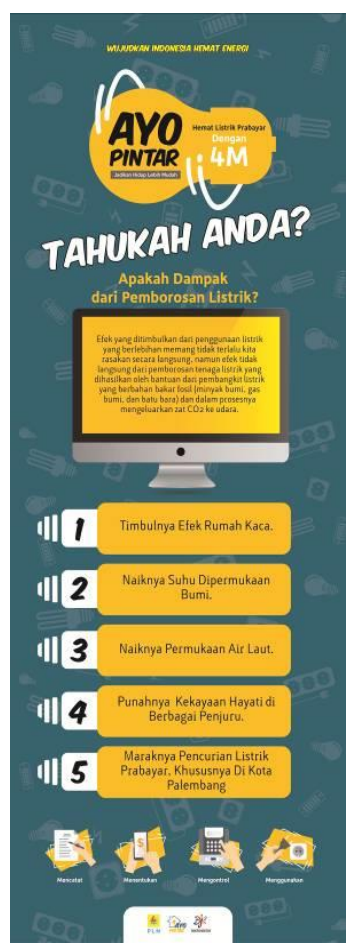

Gambar 7. Final Followup Media (X-Banner) Dibuat Oleh : Sutikno, 2018

\section{Kesimpulan}

Penghematan energi tentu sangat dibutuhan mengingat saat ini banyaknya masyarakat yang menggunakan energi itu sendiri seenaknya, tanpa memikirkan penghematan serta dampak yang ditimbulkan dari pemborosan itu sendiri. Salahsatunya yaitu energi listrik, tanpa adanya energi listrik kegiatan manusia akan terhambat, bahkan energi listrik dapat dikatakan sebagai kebutuhan primer/utama dalam kehidupan sehari-hari.

Salah satu langkah yang sudah pemerintah lakukan yaitu dengan menghadirkan listrik pintar/listrik prabayar. Sedikit berbeda dengan listrik biasanya, listrik pintar ini bekerja layaknya pulsa pada ponsel. Jadi listrik hanya akan menyala jika pulsa/token terisi. Dengan adanya listrik pintar pemerintah mengharapkan kepada 
masyarakat agar dapat menggunakan listrik dengan lebih bijak, listrik pintar ini memiliki banyak keunggulan, salahsatunya adalah masyarakat dapat mengatur pengeluaran sekaligus mengecek pemakaian listrik sendiri, keunggulan inilah yang banyak masyarakat tidak sadari.

Langkah pemerintah ini, mendapatkan banyak respon dari masyarakat. Ada yang setuju dengan listrik pintar ini, namun tidak sedikit yang tidak setuju, karena setelah pemakaian beberapa waktu. Listrik pintar ini dirasa lebih mahal daripada listrik pascabayar pada umumnya. Banyaknya stigma negatif tantang listrik pintar ini, senantiasa tidak akan membuatnya kehilangan konsumen.

Dengan adanya permasalahan tersebut, penulis ingin menghilangkan stigma negatif tentang listrik pintar ini dan senantiasa mengajak masyarakat untuk menyikapinya dengan pintar pula. Usulan pemecahan masalahnya yaitu dengan membuat perancangan yang berjudul "Cara Pintar dalam Berhemat Listrik Prabayar". Dalam perancangan ini, penulis menggunakan berbagai macam media, salahsatunya yaitu buku saku yang digunakan sebagai media utama, sedangkan poster, folding flyer sebagai media pendukung dan hang tag stiker digunakan sebagai media pendukung. Proses pengerjaan media kampanye ini, melalui beberapa tahapan, yaitu pencarian data, eksplorasi melalui sketsa hingga menjadi karya final.

\section{Daftar Pustaka}

Ebdi Sanyoto, Sadjiman. 2006. Metode Perancangan Komunikasi Visual Periklanan, Dimensi Press, Yogyakarta.

Ebdi Sanyoto, Sadjiman. 2005. Dasar-Dasar Tata Rupa dan Desain, Yogyakarta.

Kusrianto Adi. 2009. Pengantar Desain Komunikasi Visual. ANDI Yogyakarta.

M. Suyanto. 2005. MULTIMEDIA alat untuk meningkatkan Keunggulan Bersaing, ANDI, Yogyakarta

Maria Agustina S. 2010. Desain komunikasi Visual Teori dan Aplikasi, ANDI, Yogyakarta

Ratna, Nyoman Kutha. 2011. Estetika Sastra danBudaya. Pustaka Pelajar, Yogyakarta

Sanyoto Drs. Sadjiman Ebdi. 2006. Metode Perancangan Komunikasi VisuaPeriklanan, Dimensi Press, Yogyakarta

Yulius, Yosef. 2016. Pengaplikasian Golden Ratio Pada Perancangan Logo Dalam Perspektif Desain Komunikasi Visual(Diakses Pada 20 Oktober 2018)

Iswandi, Heri. 2018. Peran dan Pengaruh Tampilan Desain pada Periklanan(Diakses Pada 20 Oktober 2018)

Sumardjati, Prih. 2008. Teknik Pemanfaatan Tenaga Listrik. Direktorat Pembinaan Sekolah Menengah Kejuruan. Jakarta.

Suryatmo F. 2014. Dasar-Dasar Teknik Listrik. PT. Rineka Cipta, Jakarta.
Susan Vihma dan Seppo Vakeva. 2009. Semiotika Visual dan Semantika Produk Pengantar teori dan Praktik Penerapan Semiotika dalam Desain, JALASUTRA, Yogyakarta

Abdulkadir Muhammad. 2011. Perjanjian baku Dalam Peraktik Perusahaan Perdagangan, Citra Aditya Bhakti, Bandung. 